\title{
Development of evaluation model for consumers' satisfaction of water supply service
}

\author{
V. R. Shinde ${ }^{1}$, N. Hirayama ${ }^{2}$ \& S. Itoh $^{3}$ \\ ${ }^{I}$ Asian Institute of Technology, Thailand \\ ${ }^{2}$ National Institute for Environmental Studies, Japan \\ ${ }^{3}$ Department of Environmental Engineering, Kyoto University, Japan
}

\begin{abstract}
The objective of this study was to develop a model to evaluate and quantify customers' satisfaction (CS) with water supply service using statistical analyses, and develop a relationship between the CS and selected performance indicators of supply service systems to understand how the performance of the system is affected by changes in CS. This study used an Internet based questionnaire survey to evaluate the CS, and was conducted in the Kansai region of Japan in December 2011. A five point Likert scale was used to evaluate the responses received for the questionnaire items based on a literature review for an insight into what consumers in Japan really want or expect from their water utilities. Quantification of the CS was done by factor analysis which suggested that 'Trust in water utility' and 'Good quality water' are the main variables of the CS factor, which are both intrinsically related to water quality. In addition, 'Price of water' and 'Equity of distribution' are among the other variables that have some influence on the customers' satisfaction factor. In order to understand the impact of CS on different components of the supply system, a regression relationship was developed between the CS and selected performance indicators used to evaluate the system performance.

Keywords: consumers' satisfaction, evaluation model, factor analysis, internet based questionnaire survey, water supply.
\end{abstract}

\section{Introduction}

Water is increasingly becoming a stressed natural resource. Exploding population, indiscriminate withdrawal, and wasteful attitudes have all been 
contributing factors for the state of water that it is in today. Additionally, climate change effects on water resources further compound the problem. The Fourth Assessment Report, "Climate Change 2007", of The Inter Governmental Panel on Climate Change has eliminated many aspersions that previously shrouded both scientific and policy discussions about climate change [1]. The challenge of providing safe and reliable water supply to consumers, thus, is becoming even more pronounced for water utilities worldwide. An ideal way to gauge how utilities respond to these challenges is to conduct consumer satisfaction (CS) surveys, which are abundantly reported in literature. However, there have been relatively few studies with respect to quantifying the CS. There is a rational need for such a study, especially in developed countries where the consumers' expectations of the water quality is very high, and such quantification will help in benchmarking exercises. Additionally, it is also useful to know how different component of the supply system are affected by CS, so that processes and operations can be modified to enhance CS. This study used three performance indicators (PIs) (Financial Sustainability, Economic Value of Water and Green Water Supply) as proxies of three components of the supply system, to investigate the changing effects of CS. The objective of this study was to develop an evaluation model for quantifying customers' satisfaction of water supply service using statistical analysis, and investigating the effect of the CS on different component of the water supply system using selected PIs.

\section{Study area description}

Japan has a well-developed water supply system with over $97 \%$ of the population receiving continuous tap water supply as of 2008. Over the years, there has been a systematic progress in the nature and type of water treatment, and utilities have been making endeavors to supply quality product to its consumers. As of 2009 , approximately $76 \%$ of the utilities used rapid sand filtration, while around $22 \%$ used disinfection without filtration. Since 1995, $22 \%$ of the utilities have adopted advanced treatment processes, which include ozone-GAC treatment coupled with membrane filtration [2]. However, in the recent past there have been an increasing number of customer complaints about the quality of tap water because the consumers' expectations of water quality in Japan have been rising over the years. The traditional forms of water treatment, which use significant amounts of residual chlorine, are not very popular with the consumers because of the unpleasant taste and odor. With progress in technology and ease in obtaining information, consumers are becoming more sensitive to the type and nature of treatment processes used by the utilities. They are, hence, more likely to reject the tap water which does not meet their expectations, especially since other easy options like bottled water are easily available.

A survey conducted in Osaka City revealed that only around $22 \%$ of the male respondents and approximately $10 \%$ of the female respondents consumed tap water directly [3]. Most of the respondents (32\% males and 34\% females) preferred to use some kind of home purification system before consuming tap water while a significant number (24\% males and $25 \%$ females) were in favor of 
using bottled water. Figure 1 shows the annual trend of number of customer complaints about taste and odor for Osaka City in Japan [3]. The tap water quality provided by the Osaka Waterworks Bureau is among the best in Japan but despite that there has been an increase in the number of complaints. Thus it appears that there has been a decline in CS, which is a major concern for the utility. This study thus, seeks to examine the factors influencing the CS, and quantify it so that it can be incorporated in decision-making.

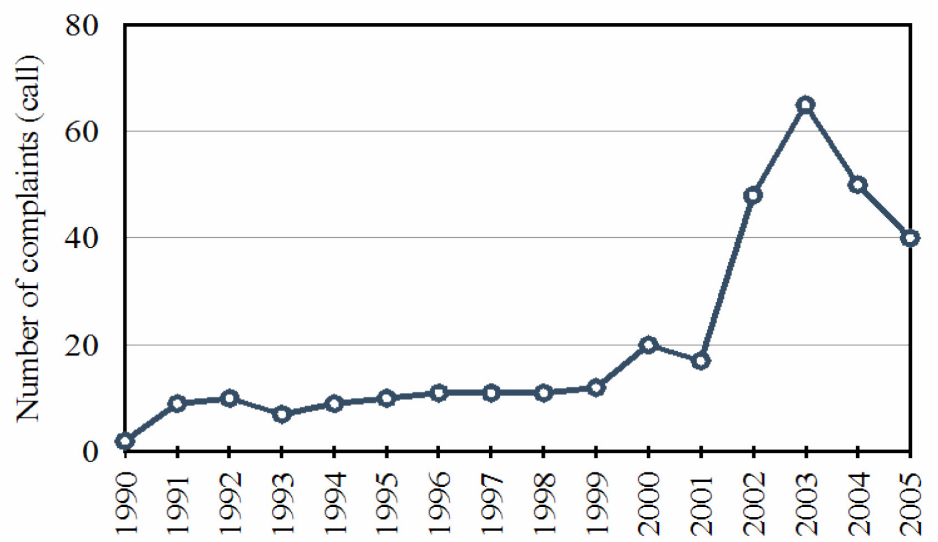

Figure 1: Customer complaints about water quality in Osaka.

\section{Evaluating consumers' satisfaction}

This study used an Internet based questionnaire survey to first evaluate the customers' satisfaction, after which it was quantified using Factor Analysis. The survey was conducted in the Kansai region of Japan in December 2011.

\subsection{Questionnaire survey design}

This survey was divided into two sections. The first section of the questionnaire contained questions pertaining to socio demographic attributes - gender, age, household income and geographic location, while the questions (eight in number) in second section were designed to extract information about the customers' satisfaction. Having an adequate sample size is very crucial because this study used Factor Analysis to quantify customers' satisfaction, where small sample sizes are known to obscure interpretation of results. Although there is no definite rule to design the size there are numerous guidelines made researchers based on practice. E.g. some suggest a minimum sample size of 100, or a sample size to item/questions ratio ranging from 10:1 to $2: 1[4,5]$. Further, the sample size also depends upon the population size, acceptable margin of error that determines the confidence interval, and degree of confidence. Because the large 
population of the Kansai region at a little over 22 Million, a sample size of 1500 was targeted to ensure $95 \%$ confidence with a margin of error of $\pm 5 \%$ [6].

A five point Likert scale was used to evaluate the responses received for the second section of the questionnaire. The Likert scale is the most widely used scale to measure people's attitudes, preferences, opinions, conceptions etc. in general [7]. Likert developed the principle of measuring attitudes by asking people to respond to a series of statements about a topic, in terms of the extent to which they agreed, thereby tapping into the cognitive and affective components of attitudes. Accordingly, the respondents in this study were given five options 'very important', 'important', 'undecided', 'less important' and 'not important' to indicate their opinion about the items in the questionnaire, and the responses were scored from 5 to 1 in decreasing order of importance.

To be able to decide upon the contents of the questionnaire, a literature review was conducted to gain an insight into what consumers in Japan really want or expect from their water utilities, and four major issues (questions) were identified. As pointed out earlier a number of studies and surveys carried out in various regions of Japan indicate that inoffensive taste, odor and smell of water are top priorities for consumers [3], suggesting that good water quality is crucial to customers' satisfaction. Drinking water is essentially the most basic service and consumers place their trust in the utilities to provide them with safe drinking water, which is a huge responsibility for the utilities. This is particularly significant with respect to the presence of harmful elements in the water that cannot be detected by smell, taste or odor. It was reported that people are less concerned about tap water quality when their trust in the waterworks system increases [8]. Hence, trust in water supply utilities is another aspect of the water supply system, which is crucial from a consumer's point of view. As society becomes more progressive, consumers expect more transparency and access to information regarding the supply system. It was showed that information that increases controllability about the risk of drinking water quality reduces citizens' concern in that respect [9]. Providing the information consumers want is a part of the customer services operations, which makes customer service an important aspect of customers' satisfaction. Next, the average unit price of water and sanitation in Japan per cubic meter is very cheap (\$1.85), which is markedly lower than other OECD countries (Organization for Economic Cooperation and Development) like Australia (\$2.44), Sweden (\$3.59), France (\$3.74), England and Wales (\$3.82), Finland (\$.4.41), Germany (\$5.72) and Denmark (\$6.70) (OECD 2010). This points out to the possibility that consumers are accustomed to subsided water, and may be reluctant to pay more, making low water prices a possible component of customers' satisfaction.

Conversely, another four issues were included in the questionnaire, which were hypothesized to be significantly less important in terms of customers' satisfaction - employee productivity in utilities, financial state of utilities, research and development in utilities and equity of distribution. Each of these aspects are crucial from a utility's point of view but may not be as important from the consumers' point of view. The reason of including the last four items in the questionnaire was to facilitate the application of factor analysis, which would 
Table 1: Questionnaire items in the survey.

Questionnaire item

Trait

Good tap water quality

Trust in water supplier

Consumers' point of view

Customer service

(Consumers' satisfaction)

Price of water

Employee productivity in utilities

Financial state of utilities

Utilities' point of view

Research \& Development in utilities

(Consumers' non-concern)

Equity of distribution

help to quantify the factor of customers' satisfaction. Table 1 presents the eight questionnaire items and the traits that they were expected to measure.

\subsection{Factors influencing CS}

1648 responses were received, based on which Figure 2 was prepared showing the summative scores for each question, which can be divided into two groups according to the magnitude of the summative scores. Accordingly, where it is

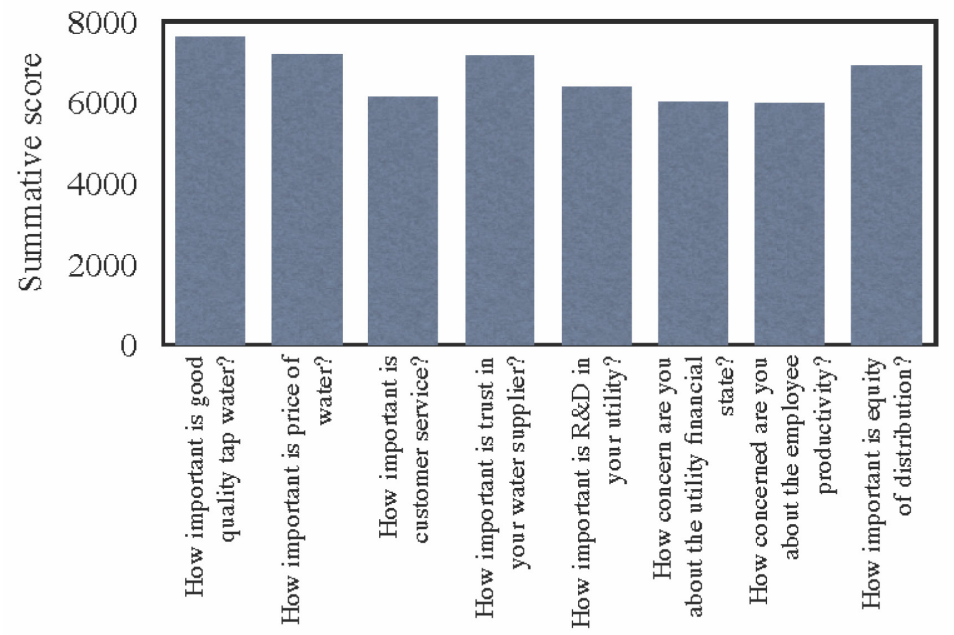

Figure 2: $\quad$ Summative scores for total responses for each questionnaire item. 
seen that 'water quality', 'trust in utility', 'equity of distribution' and 'water price' have the highest scores, and all except 'equity of distribution' correspond to the customers' satisfaction as established from literature.

\subsection{Quantifying CS}

Quantification of the CS was done using factor analysis. The factor analysis resulted in a Kaiser-Meyer-Olkin (KMO) measure of 0.850 , which is considered meritorious, suggesting that the sample is suitable for factor analysis. Two factors were extracted from the factor analysis, details of which are presented in Table 2.

Table 2: $\quad$ Factor matrix with varimax rotation.

\begin{tabular}{c|c|c|cc}
\hline & \multicolumn{2}{|c|}{ Loading } & \multicolumn{2}{c}{ Factor Score Coefficient } \\
\hline Questionnaire item & Factor 1 & Factor 2 & Factor 1 & Factor 2 \\
\hline Employee productivity in utilities & $\mathbf{0 . 7 5 0}$ & 0.206 & 0.484 & -0.156 \\
Financial state of utilities & $\mathbf{0 . 7 0 8}$ & 0.258 & 0.387 & -0.083 \\
Research \& Development in utilities & $\mathbf{0 . 4 8 7}$ & $\mathbf{0 . 5 2 8}$ & 0.112 & 0.197 \\
\cline { 2 - 2 } Trust in water supplier & 0.292 & $\mathbf{0 . 6 4 3}$ & -0.054 & 0.347 \\
Good quality tap water & 0.096 & $\mathbf{0 . 5 9 5}$ & -0.128 & 0.313 \\
Equity of distribution & 0.390 & $\mathbf{0 . 4 7 6}$ & 0.046 & 0.162 \\
Price of water & 0.202 & $\mathbf{0 . 4 0 3}$ & -0.014 & 0.144 \\
Customer service & 0.355 & $\mathbf{0 . 3 9 7}$ & 0.048 & 0.112 \\
\hline Variance extracted (\%) & 43.72 & 12.39 & & \\
\hline
\end{tabular}

The combined variance extracted by the factors was $56.11 \%$, which is suitable for this kind of analysis. The first two columns of the table show the loading of each questionnaire item onto the factors. Loading, in this context, is the correlation between the questionnaire items and the factors. High loading variables are understandably crucial, and thus in this study an item with loading of more than 0.4 was considered to make a significant contribution to the factors.

To have a better understanding of the information elucidated by the components, varimax rotation was performed. The goal of rotation is to simplify and clarify the data structure. Rotation cannot improve the basic aspects of the analysis, such as the variance extracted from the items, but merely rearranges the data structure by increasing the loading of items on one factor and reducing it on others. Among the different rotation techniques, varimax rotation is the commonest [10]. From Table 2, it is apparent that there are three items that significantly load onto the first factor - Employee productivity is utilities, Financial state of utility and Research and Development in Utility. On the other 
hand, the significant loaders on the second factor are - Trust in water supplier, Good quality tap water, Research and Development in utilities, Equity of distribution and Price of water. A majority of these items were hypothesized to form the 'Consumers' Satisfaction', the exception being Research and Development in utilities. Hence it was suggested that the second factor could be considered as the customers' satisfaction factor. The Research and Development in utilities item loads on to both the factors, and is thus called a cross-loader. Although cross-loaders are not desirable and are usually dropped, retaining the item is the prerogative of the researcher, especially if there are very few cross loaders [10]. In this study, cross loading item was retained so that there are at least three variables contributing to the first factor, given that factors with less than 3 items are usually unstable. As a result, it is clear that 'Trust in water utility' and 'Good quality water' are the main variables of the customers' satisfaction factor, which are both intrinsically related to water quality. Hence, it can be said that water quality is the most significant aspect affecting CS in the Kansai region of Japan.

\subsection{Effect of CS on performance of water supply system}

In order to understand the effect that CS has on the performance of the water supply system, a relationship was developed between the CS and selected PIs. Three PIs were considered for the relationship analysis, Financial Sustainability (FS), Green Water Supply (GWS) and Economic Value of Water (EV). To establish a relationship between the CS and the three categories of PIs, the questionnaires were classified according to service areas, and ten areas were selected from where the maximum responses were received. The number of service areas to be selected should be enough to model the desired relationship, and this study refrains from setting any criteria in this regard. Ten service areas were selected because this number was thought to be sufficient for Multiple Linear Regression (MLR, used to develop an equation to relate the CS with the three PIs); while at the same time eased the burden of data collection. Next, the water utilities for each of these service areas were identified, and were requested to provide raw data in order to calculate the mathematical magnitude of the PIs, which was done using PI system developed in our earlier study [11]. Table 3 shows the estimated values of CS and PIs in the selected water utilities in Kansai Region, Japan.

A Multiple Linear Regression (MLR) model was then developed with the PIs of the ten areas as explanatory variables and CS as the dependent variable. The MLR model performance was evaluated using the coefficient of determination (R2) and the adjusted coefficient of determination (adjusted R2). R2 is the proportion of variability in a data set that is accounted for by a statistical model, whereas adjusted R2 is a modification of R2 that adjusts for the number of terms in a model. R2 always increases when a new term is added to a model, but adjusted R2 increases only if the new term improves the model more than would be expected by chance. The analysis resulted in a R2 and adjusted R2 values of 0.596 and 0.555 . Because there is not a very significant difference between the 
Table 3: $\quad$ CS and magnitudes of selected water utilities in Kansai region.

\begin{tabular}{ccc|ccc}
\hline \multirow{2}{*}{ Water Utility } & \multicolumn{2}{c|}{ CSWQ } & \multicolumn{3}{c}{ Performance Indicators } \\
\cline { 2 - 6 } & Mean & Median & FS & GWS & EV \\
\hline Osaka City & 1.91 & 1.87 & 107.87 & -61.09 & 690.48 \\
Kobe City & 1.81 & 1.85 & 93.34 & -35.68 & 789.15 \\
City of Kyoto & 1.82 & 1.84 & 104.74 & -39.59 & 813.72 \\
Sakai City & 1.83 & 1.85 & 101.15 & -5.58 & 838.76 \\
Amagasaki & 1.98 & 2.03 & 107.41 & -62.20 & 796.46 \\
Nishinomiya & 1.76 & 1.71 & 101.73 & -35.17 & 794.79 \\
Suita & 1.96 & 1.98 & 98.42 & -46.94 & 622.35 \\
Hirakata & 1.82 & 1.85 & 109.82 & -68.32 & 776.83 \\
Otsu & 1.85 & 1.70 & 112.75 & -67.40 & 729.83 \\
Nara & 1.71 & 1.69 & 107.75 & -20.07 & 833.31 \\
\hline
\end{tabular}

two values, the MLR model appears to be reliable. Based on the coefficients of the MLR model, as a result of the analysis, eqn. (1) was developed to link the CSWQ with the selected PIs.

$$
\mathrm{CSWQ}=2.083-0.004 \mathrm{FS}-0.001 \mathrm{GWS}+0.001 \mathrm{EV}
$$

Eqn. (1) suggests that water utilities can estimate the magnitude of CS using the values of PIs in their business evaluation process. This will help them in understanding the impacts of CS on the various processes and components of the supply system. In addition, we strongly believe that this model can lead to develop a generalized methodology to design the tradeoff between meeting CS and reducing energy use for water utilities in order to mitigate the impacts of climate change.

\section{Conclusions}

The objective of this study was to develop a model to evaluate and quantify customers' satisfaction (CS) with water supply service using statistical analyses, and develop a relationship between the CS and selected performance indicators of supply service systems to understand how the performance of the system is affected by changes in CS. Using an internet based questionnaire survey, conducted in the Kansai region on Japan in December 2011, and Factor Analysis, the "CS factor" was quantified. The results suggested that 'Trust in water utility' and 'Good quality water' are the main variables of the CS factor, 
which are both intrinsically related to water quality. In addition, 'Price of water' and 'Equity of distribution' are among the other variables that have some influence on the customers' satisfaction factor. A good relationship, using multiple linear regression, was developed between the CS and selected components of a performance indicator system, which has very potential to be used as a planning and management instrument for ensuring sustainable water supply.

\section{References}

[1] IPCC, Climate Change 2007, Fourth Assessment Report, 2007.

[2] JWWA, Japan Waterworks Statistical Book, Japan Water Works Association, 2008.

[3] Itoh, S., Shiro, S., Hirayama, N., Echigo, S. and Ohkouchi, Y, Psychosocial considerations on strategies for improving customers' satisfaction with tap water based on casual modelling, Journal of Japan Water Works Association, 76(4), 25-37, 2007.

[4] Kline, P., Psychometrics and Psychology, Academic Press, London, 1979.

[5] Velicer, W. F., and Fava, J. L., Effects of variable and subject sampling on factor pattern recovery, Psychological Methods, 3, 231-251, 1998.

[6] Statistics Bureau, Ministry of Public Management, Home Affairs, Posts and Telecommunications, Population census of Japan and Annual Report of current population estimates 2007, 2011.

[7] Wu, C. H., An empirical study on the transformation of Likert-scale data to numerical scores, Applied Mathematical Sciences, 1(58), 2851-2862, 2007.

[8] Itoh, S., Hirayama, N., Kagawa, K. and Shiro, S., Development of an information disclosure technique for reducing citizens' concern on tap water quality, Advances in Asian Environmental Engineering, 5(1), 31-38, 2006.

[9] Hirayama, N., Itoh, S., Kagawa, K. and Shiro S., Analysis of risk perception on drinking water quality from the viewpoint of controllability, Journal of Japan Water Works Association, 74(1), 2-11, 2005.

[10] Costello, A.B. and Osborne J., Best practices in exploratory factor analysis: four recommendations for getting the most from your analysis. Practical Assessment Research and Evaluation, 10(7). Available online: http://pareonline.net/getvn.asp?v=10\&n=7, 2005.

[11] Shinde, V. R., Hirayama, N., Mugita, A., and Itoh, S., Revising the existing performance indicator system for small water utilities in Japan, Urban Water Journal, DOI: 10.1080/1573062X.2012. 739628, 2012. 